\title{
Design Approaches to Improve Organic Solar Cells
}

\author{
Fahmi Fariq Muhammad ${ }^{*}$
}

Department of Physics, Faculty of Science and Health, Koya University, Koya, Kurdistan Region, Iraq

\begin{abstract}
Organic solar cells (OSC)s are valuable economical and environmental friendly devices capable to generate electricity from sunlight. This is because of their simple fabrication process and minimal material usage in comparison to the inorganic solar cells. OSCs have not been widely commercialized yet because of their relatively low power conversion efficiency and stability problem. It is expected that these obstacles will be surmounted in a foreseeable future upon rigorous research studies performed in the field. This paper is devoted to reviewing the design related strategies that can be taken to enhance OSC performance. These strategies can be accomplished through modulating the architecture of the devices and by considering the alignment of the molecular energy levels between their active layer components.
\end{abstract}

Keywords: Organic solar cell, Nanostructure material, OSC performance, OSC efficiency, OSC improvement.

\section{INTRODUCTION}

The continuous demand for energy and the limiting supply of its today's main sources (petroleum, natural gas, and coal) with their detrimental long term effects on the environment necessitates a rapid development into the clean and renewable energy sources. The only sustainable source that can supply electric power with its capability of protecting our environment from being polluted is thought to be solar energy [1-3]. Solar energy can be exploited to generate electricity by means of solar cell devices in a technology known as photovoltaic, PV technology. The most widely used material in PV fabrication is crystalline silicon, $\mathrm{c}-\mathrm{Si}$ representing over $90 \%$ of the global commercial PV module production in its various forms [4]. Manufacturing of inorganic based SC is expensive due to strong requirements to the high purity of this material and the techniques used in the devices fabrication [5]. Besides, emissions to the environment are mainly occurred from using fossil-fuel based energy in producing the materials for inorganic solar cells [6].

Over the last two decades great efforts have been made to develop the low cost and ambient temperature processing solar cells based on organic and polymeric materials [7-10]. Despite easy fabrication of these devices, they are able to show extra important features, such as flexibility, light weight, and degradability for recycling purposes. OSC is a green technology, which is basically made from those materials that carbon atoms are participating in their chemical structures. OSCs are seen to be the most plausible candidates with substantial future prospects consisting of

*Address correspondence to this author at the Department of Physics, Faculty of Science and Health, Koya University, Koya, Kurdistan Region, Iraq;

Tel: +964-7701935331; E-mail: fahmi982@gmail.com conjugated polymers, fullerenes $\left(\mathrm{C}_{60}\right.$ and its derivatives), and carbon nanotubes, CNTs [11-17]. However, due to their low efficiencies of about $9 \%[18,19]$ and stability problem [20], they are still far from being commercialized widely, while at least $10 \%$ of stable power conversion efficiency is required for practical applications [21, 22]. The unsolved issues of low efficiency, and short life time, necessitate rigorous research studies to be performed covering from materials analysis to the devices fabrication and characterization. Nevertheless, relatively little information is known about the exact correlation between the devices parameters and their materials performance, still some of the OSCs parameters are not fully understood [23, 24]. Figure 1 shows a prototype structure of OSC device. Indium-tin-oxide (ITO) is normally utilized as first electrode. The most commonly used second electrode is one of these metals; aluminum, calcium, magnesium, or gold.

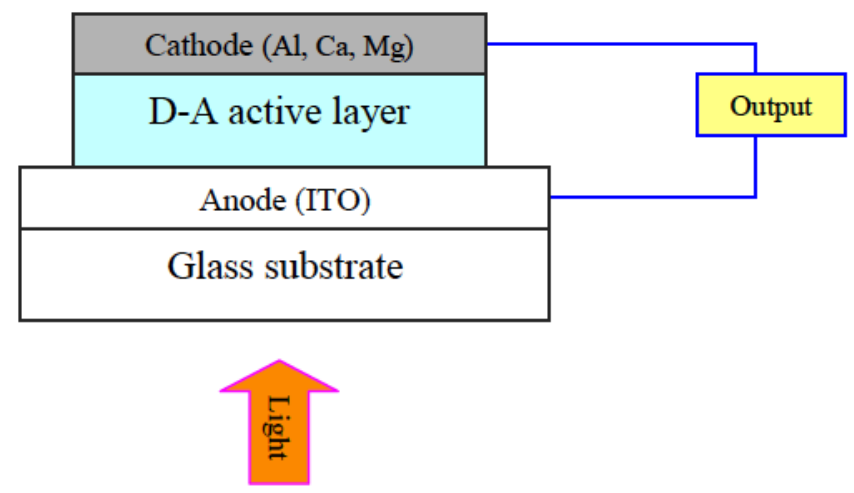

Figure 1: Prototype structure of organic solar cells.

It is clear that upon the absorption of light by OSCs, excitons (bound electron-hole) are formed in the donoracceptor (D-A) active layer, followed by the exciton diffusion and dissociation, which occurs at the D-A interfaces via an ultra-fast charge transfer. 
Subsequently, the separated free electrons and holes transport through individual percolating pathways, and then they are extracted by the corresponding electrodes. Hence, one might conclude that the device performance can be approached by improving factors contributing in the processes of light absorption, exciton diffusion/dissociation, charge transport, and charge collection.

One major obstacle in front of OSCs is how to make excitons dissociate effectively into free charge carriers. Another challenge, which is common in both of organic and inorganic solar cells, is the full collection of photogenerated charge carriers by the correspondence electrodes (negative and positive electrodes). In the organic materials, especially disordered ones, carrier mobility is several orders of magnitude smaller than that in crystalline inorganic semiconductors. This imposes restriction on the maximum thickness of organic photovoltaic devices and makes them to have very thin active layers (in nanometers scale). Furthermore, D-A organic components suffer from an imbalance transport of electron and hole carriers. Accumulation of less mobile charge carriers in the active layer will hamper charge collection at the electrodes and thereby drastically reduce the solar cell efficiency. Another problem is the difficulties in an efficient harvest of excitons. Because of a large binding energy, intrinsic dissociation of excitons into free carriers is virtually impossible. Due to this, diffusion of excitons towards either charge transfer centers or D-A interfaces is a prerequisite for charge photogeneration [25]. Therefore, different practical approaches are needed to be undertaken to overcome these

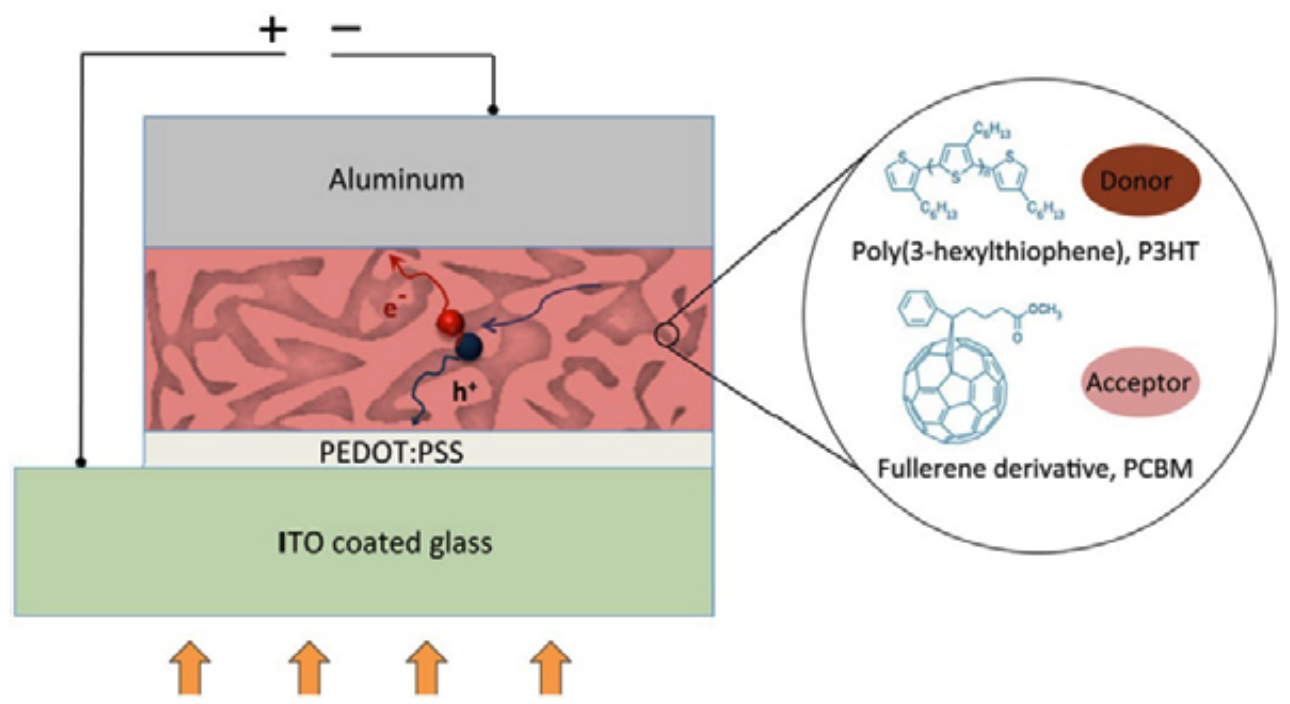

bottlenecks and hence to produce efficient OSC fabrication. The next sections will provide an interesting overview of these approaches.

\section{BULK HETEROJUNCTION STRUCTURES}

The idea behind bilayer heterojunction, which consists of two layers of D-A, is to use two materials with different electron affinities, LUMOs and ionization potentials, HOMOs [26]. By this, favorable exciton dissociation is obtained; the electron will be accepted by the material with the higher electron affinity while the hole by the material with the lower ionization potential [27]. The main drawback of this concept resides in the rather short diffusion length of excitons $(5-15 \mathrm{~nm})$ [28]. Indeed, only those excitons that are created within a distance from the D-A interface shorter than their diffusion length may contribute to the photocurrent generation [25]. This limits the photocurrent and hence the overall performance of bilayer organic solar cells. To overcome this limitation, the surface area of the D-A interface needs to be increased. This can be achieved by creating a mixture of donor and acceptor materials with a nanoscale phase separation resulting in a three dimensional interpenetrating network called the bulk heterojunction like shown in Figure 2. Bulk heterojunction concept suggests the goal of achieving a larger interfacial area between the electron and hole transporting materials. The photocurrent achieved by bulk heterojunction devices are up to several milliamperes per square centimeter, improving drastically the efficiencies over that of bilayer strucutres $[24,29]$. It has been proved that solution-processed bulk heterojunction structures with D-A blends sandwiched between the anode and cathode are the

Figure 2: Bulk heterojunction structure for OSCs. 
most promising alternative to realize large-scale solar cell production [30, 31].

The bulk heterojunction device is similar to the bilayer device with respect to the D-A concept, but it exhibits a vastly increased interfacial area dispersed throughout the bulk. The bulk heterojunction requires percolated pathways for both phases throughout the volume, i.e., a bicontinuous and interpenetrating network. Therefore, the nanoscale morphology in the bulk D-A active layer is more complicated to be controlled well in terms of the phase separation between the donor and acceptor regions and hence possibly the leakage current persists due to the insufficient contact of the acceptor phase with the cathode electrode and donor phase with the anode electrode [32]. The bulk heterojunction devices used today consist, in general, of a poly(4-tyrenesulfonate) (PEDOT-PSS) covered ITO substrate, coated with a single photoactive bulk heterojunction layer (e.g., polymer-fullerene mixtures) closed by a low work function cathode such as $\mathrm{Al}$ [33].

\section{MULTILAYER STRUCTURES}

It is known that each organic material has a unique optical band gap and a broad absorption spectrum of sunlight is not easy to be achieved by a single organic layer. Therefore, multiple layers and stacked tandem cell structure, in which each layer absorbs a different light wavelength, have been proposed to mostly resolve the limited absorption problem. Organic materials have higher absorption coefficient than that of inorganic materials. Therefore, about $300 \mathrm{~nm}$ film is thick enough to absorb the most incident light [13]. However, the thickness is ultimately limited by the short exciton diffusion length and low charge carrier mobility [17] since the balance between the light absorption and

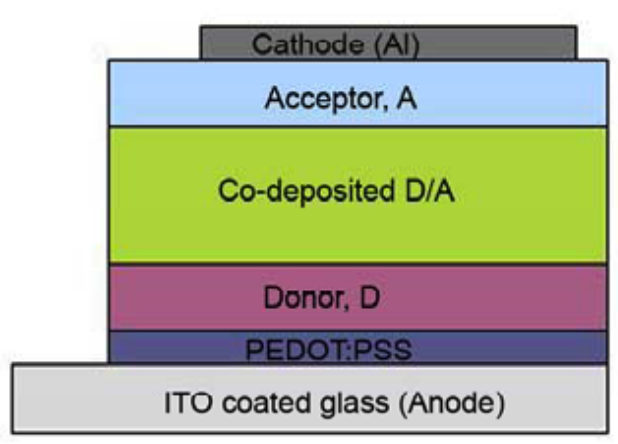

(a) the charge transport plays a crucial role in the device performance. As a result, the optimized thickness for most of OSCs is less than $100 \mathrm{~nm}$ [13]. Apart from bulk heterojunction structure that was discussed previously, several materials and device structures have been developed to obtain high short circuit current density, $J_{s c}$. The concept of tri-layer organic p-i-n junction [34], in which i-layer is a co-deposited layer of two different organic semiconductors is another approach, as shown in Figure 3a. Co-deposited layers have a vast number of heteromolecular (donor-acceptor) contacts acting as efficient photocarrier generation sites [28]. Additionally, tandem structure as an effective approach to enhance the light harvesting by means of stacking multiple cells with complementary absorption spectra has also been proposed (see Figure $3 \mathbf{b}$ ). The limits to power conversion efficiency and photovoltage can be breached through fabrication of tandem solar cells [3537]. A tandem solar cell consists of two stacked solar cells made from materials with different optical gaps. Initially, light is absorbed by the higher-gap cell hence the lower energy photons pass through the higher gap device and then photons are absorbed by the second cell. There is a conductive layer connecting the two cells accordingly, which works as a site for charge recombination. However, in terms of device fabrication, there are difficult tasks such as optimizing the layers thickness, selection of suitable materials, and recombination sites that have to be treated with a great caution. Figure $\mathbf{3 b}$ shows a representative tandem solar cell with two stacked cell structure having a gold metal, Au layer as the conductive layer between the two stacked cells to provide the recombination site.

\section{EXCITON BLOCKING LAYER}

The active layer of bulk heterojunction structure is sandwiched between the anode and cathode

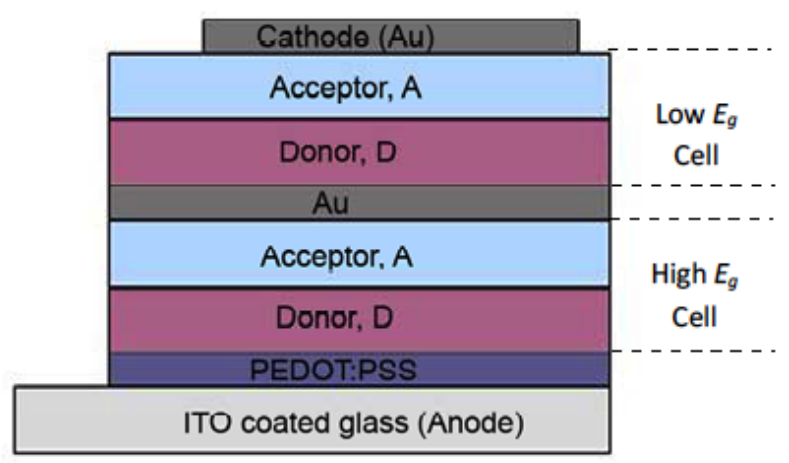

(b)

Figure 3: The structure of (a) multilayer organic $p$-i-n solar cells and (b) organic tandem solar cells. 
electrodes, in which both donor and acceptor materials are in direct contact with the electrodes. So it is possible for the acceptor material to transfer electrons to the hole-collecting anode and for the donor to transfer holes to the electron-collecting cathode, thereby producing a large leakage current and lowering the performance of the device. In order to tackle these problems, interfacial buffer layers can be inserted between the active layer and electrodes to enhance the collection of the photogenerated charges and to reduce the leakage current [31]. In a study in which an exciton blocking layer, EBL of bathocuproine, BCP was incorporated, photovoltaic properties of devices based on pentacene/PCBM were investigated [38]. It was seen that a thin layer of BCP has improved the EQE and charge carrier collection in the devices. More recently, tris (8-hydroxyquinolinate) aluminium, Alq3 was also used between the cathode electrode and acceptor materials [39, 40] (see Figure 4). It was observed that this has led to increase in both efficiency and stability of the OSC devices.

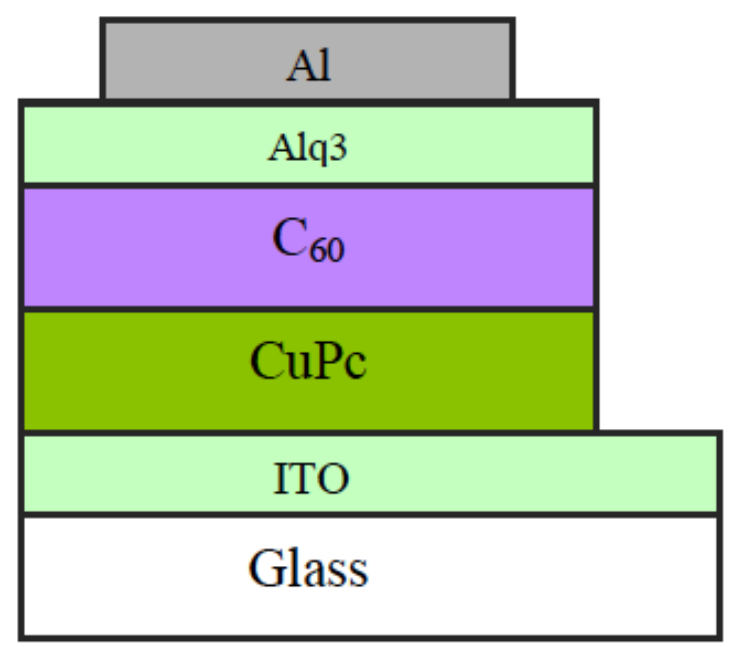

Figure 4: An OSC device incorporating exciton blocking layer of Alq3 between the cathode electrode and acceptor material.

Similar to the cathode interface, atoms from the anode electrode can react with the organic material. Indium atoms from indium tin oxide, ITO electrode were found to diffuse into the organic layer, where it acts as trapping site for the charge carriers [27]. One strategy that is used to minimize indium and oxygen diffusion is to put an interfacial hole-transporting layer, such as poly(3,4-ethylenedioxythiophene):poly(4-styrenesulfonic) acid, PEDOT-PSS between ITO and the active material. This layer serves to smooth out the uneven surface of ITO and provides larger injection of holes into the anode electrode. Figure $\mathbf{5}$ shows a device, in which after insertion of a thin PEDOT:PSS layer $(\approx 35$ $\mathrm{nm}$ ) between the active layer and anode electrode, the efficiency of the device was pronouncedly increased [24].

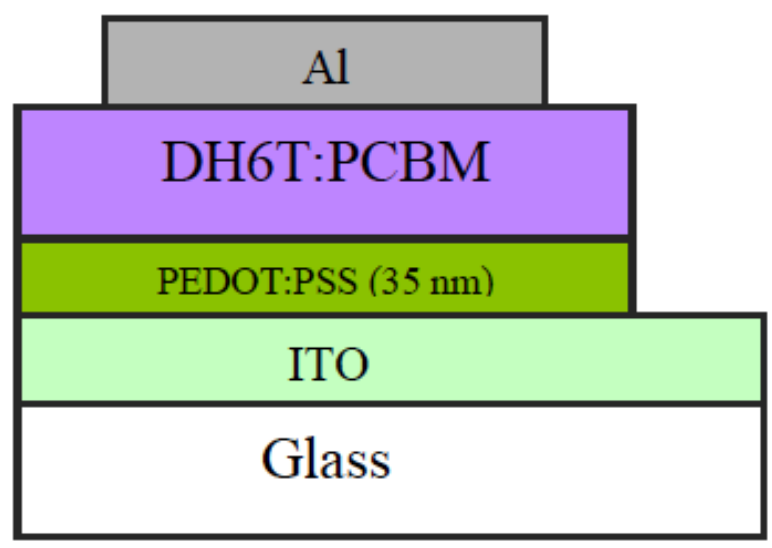

Figure 5: An OSC device incorporating exciton blocking layer of PEDOT:PSS between the anode electrode and acceptor material.

\section{DOUBLE CABLE POLYMER}

It was understood that the control of nanoscale morphology in bulk heterojunction structure was not easy. The degree of the phase separation between D-A and domain size depend on solvent choice, speed of evaporation, materials solubility, miscibility of the donor and acceptor components, annealing temperature, etc. One strategy towards increasing the D-A phase control is to covalently link donor and acceptor molecules to get some sort of polymers called the double cable polymers. Researchers [41-43] have synthesized a pendant fullerene moieties and polythiophene backbone with covalently bound tetracyanoanthraquino-dimethane, TCAQ moieties (donor-acceptor double-cable polymer), respectively, aiming at utilizing these structures in organic solar cells. Even though the synthesized soluble cable polymers have shown some promising results, the fully optimized double-cable polymers are still not achieved. As the complexity of the designed systems increase, the more critical it becomes to optimize design parameters. The realization of effective double cable polymers will bring the D-A heterojunction at a molecular level. Figure $\mathbf{6 a}$ shows a schematic representation of this system, while Figure $\mathbf{6 b}$ shows an alternative approach to double cables polymer, known as block copolymers, consisting of donor and acceptor blocks linked side by side together. In general, block copolymers $[44,45]$ are well recognized for phase separation and ordered domains formation, similar to those of the double cable polymers. Stalmach et al. [46] synthesized a block copolymer consisting of an electron acceptor block and 


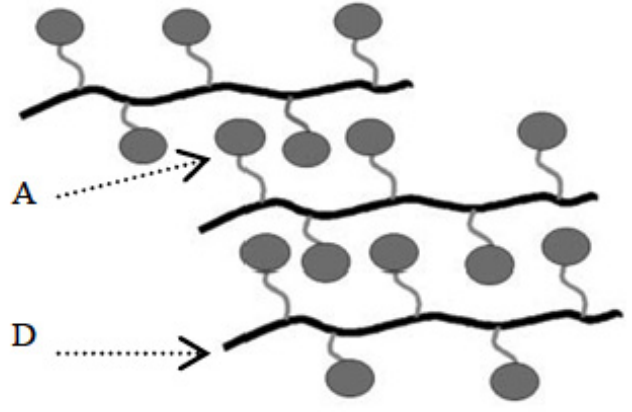

(a)

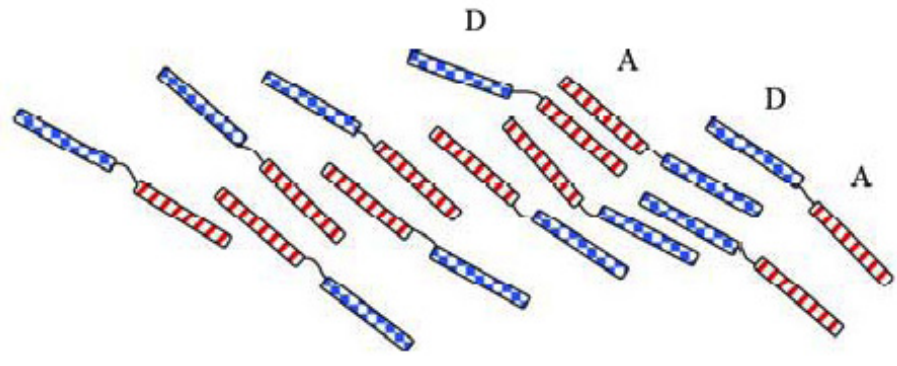

(b)

Figure 6: Shows (a) schematic representation of a realistic double cable polymer and (b) self-assembled layered structure of diblock copolymers.

an electron donor block by means of atom-transfer radical addition, aiming to enhance the photovoltaic efficiency of the PPV- $\mathrm{C}_{60}$ system (PPV $=\operatorname{poly}(p-$ phenylenevinylene)). Since the solubility of such complicated structures is very limited, the practical handling for device fabrication is cumbersome [27].

\section{ENERGY BAND ALIGNMENT}

The discovery of conjugated polymers stimulated the research field of organic electronics, thereby developing a variety of organic based devices such as, solar cells, light-emitting diodes, field-effect transistors, and memory devices. The emergence of the fields can be tracked back to the mid-1970 when Shirakawa reportedly prepared the first polymer (polyacetylene) by accident, subsequently Heeger and MacDiarmid discovered that the polymer would undergo an increase in conductivity by 12 orders [47]. The most important functionality of the organic materials is the large polarizability of their extended $\pi$-conjugated electron systems formed by the delocalization of the $p_{z}$ orbitals of the carbon atoms [14]. Due to this basic functionality, upon the absorption of sun light, these materials can show the photo-induced charge carriers and transport properties by hopping process along their conjugated backbone. Hence, most of the organic materials have attracted considerable attention to be exploited in the fabrication of electronic and optoelectronic devices [48]. In particular, two types of materials are usually selected as photovoltaic active layers in the fabrication of OSCs. The first layer must be conductive to holes. This is referred to as donor, while the second layer is conductive to electrons and known as acceptor. Regardless of whether the device is produced in a bilayer or bulk heterojunction structure, it is of great importance the HOMO and LUMO energy levels of the D-A system are matched well to facilitate efficient exciton generation, dissociation and charge transport properties. The basic process of the photo-induced charge transfer between a donor, $D$ molecule and an acceptor, A molecule can be described as follows [49]:

Step 1: $D+A \rightarrow D^{*}+A$ (photoexcitation of D)

Step 2: $\quad D^{*}+A \rightarrow(D-A)^{*} \quad$ (excitation delocalized between $D$ and $A$ )

Step 3: $\quad(D-A)^{*} \rightarrow\left(D^{\delta+}-A^{\delta-}\right)^{*} \quad$ (polarization of excitation: partial charge transfer)

Step 4: $\quad\left(D^{\delta+}-A^{\delta-}\right)^{*} \rightarrow\left(D^{\bullet+}-A^{\bullet-}\right) \quad$ (ion radical pair formation)

Step 5: $\quad\left(D^{\bullet+}-A^{\bullet^{-}}\right) \rightarrow D^{\bullet+}+A^{\bullet^{-}} \quad$ (complete charge separation)

Table 1 shows some representative donors and acceptors including their HOMO and LUMO energy levels $[50,51]$ with their molecular structures. Fullerenes are considered the best electron acceptors so far. This is because of (i) ultrafast $(\sim 50 \mathrm{fs})$ photoinduced charge transfer that is happened between the donors and fullerenes, (ii) fullerenes exhibit high mobility, for example, $\mathrm{C}_{60}$ has shown field effect electron mobility of up to $1 \mathrm{~cm}^{2} \mathrm{~V}^{-1} \mathrm{~s}^{-1}$ and (iii) fullerenes show a better phase segregation in the blend films [13, 49]. Among the organic donor materials concerned, sexithiophene, 6T shows the highest mobility when they are used as hole transporting layers $[52,53]$. By improving the solubility of sexithiophenes through the addition of hexyl side chains to $\alpha$ sexithiophene (6T) [54], it was possible to synthesize $\alpha, \omega$-dihexyl-sexithiophene, DH6T semiconductor, which was characterized by reasonable field-effect mobility reaching as high as $0.1 \mathrm{~cm}^{2} / \mathrm{V} . \mathrm{s}[55,56]$. 
Table 1: Examples of Donor and Acceptor Organic Materials Including their Basic Structural and Energy Levels Information

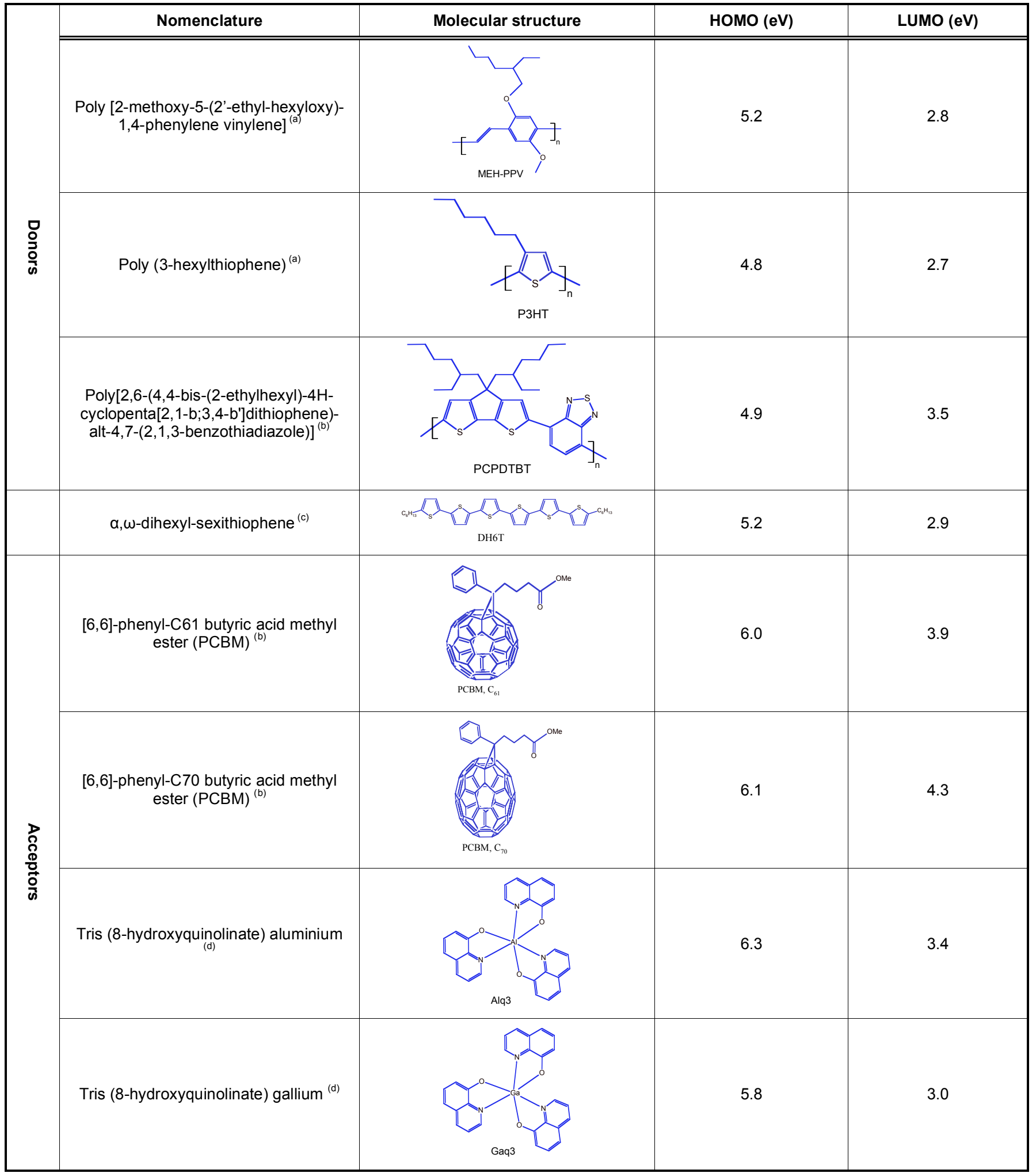

${ }^{(a)}[57],{ }^{(b)}[37],{ }^{(c)}[51],{ }^{(d)}[50]$.

Benefited by the high carrier mobility of DH6T and PCBM, and their appropriate energy band alignment various architectures of organic solar cells based on
DH6T/PCBM have been investigated [24]. Interestingly, if a ternary bulk heterjunction structure is considered, then the right choice of materials based on their energy 


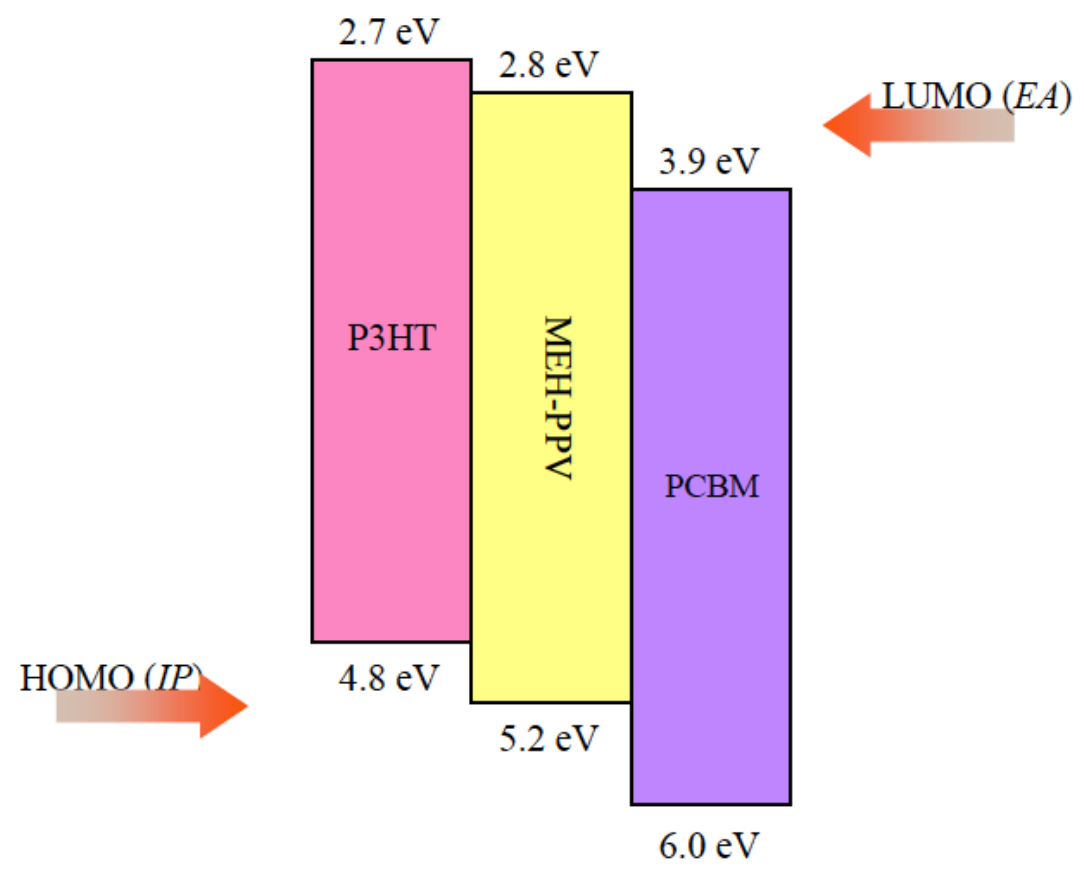

Figure 7: The correct HOMO and LUMO energy band alignment of P3HT, MEH-PPV and PCBM for OSCs application.

bands alignment is of initial necessity. Figure 7 shows an example of such alignment between the molecular energy levels of P3HT/MEH-PPV/PCBM components (D-A-A), in which a correct HOMO and LUMO energy band alignment can be realized for OSC application.

\section{OUTLINE}

The simple and low cost fabrication process of organic solar cells makes them attractive candidates for generation of electricity. The performance enhancement of these devices is of prior request by the researchers in the field. This can be accomplished upon rigorous research studies performed through materials analysis to the devices fabrication and characterization, thereby realizing valuable strategies to improve the performance of these devices. The architecture of the active layer plays a vital role in defining the overall efficiency of OSCs. In this way, various approaches can be utilized to modulate the device components including heterojunction and multilayer structures, insertion of excitons blocking layers, designing the double cable or di-block copolymers along with the optimum selection for the HOMO and LUMO energy levels between the cells components.

\section{ACKNOWLEDGEMENT}

Author would like to thank Physics Department, Koya University.

\section{REFERENCES}

[1] Durisch W, Tille D, Wörz A, Plapp W. Characterisation of photovoltaic generators. Applied Energy 2000; 65(1-4): 27384.

http://dx.doi.org/10.1016/S0306-2619(99)00115-4

[2] Gibson TL, Kelly NA. Solar photovoltaic charging of lithiumion batteries. Journal of Power Sources 2010; 195(12): 392832.

http://dx.doi.org/10.1016/j.jpowsour.2009.12.082

[3] Kalogirou SA. Solar Energy Engineering, Processes and Systems. First ed. London WC1X 8RR, UK: Elsevier Inc.; 2009.

[4] Foster R, Ghassemi M, Cota A. Energy and the Environment. Ghassemi A, editor. Boca Raton, FL 33487-2742: Taylor and Francis Group, LLC; 2010.

[5] Skompska M. Hybrid conjugated polymer/semiconductor photovoltaic cells. Synthetic Metals 2010; 160(1-2): 1-15. http://dx.doi.org/10.1016/j.synthmet.2009.10.031

[6] Fthenakis VM, Kim HC. Photovoltaics: Life-cycle analyses. Solar Energy 2011; 85(8): 1609-28. http://dx.doi.org/10.1016/j.solener.2009.10.002

[7] Jia Y, Yang L, Qin W, Yin S, Zhang F, Wei J. Efficient polymer bulk heterojunction solar cells with cesium acetate as the cathode interfacial layer. Renewable Energy 2013; 50(0): 565-9.

http://dx.doi.org/10.1016/j.renene.2012.07.012

[8] Sharma GD, Saxena D, Sangodkar SG, Roy MS. Study of some organic polymeric materials for electrical and optoelectrical devices. Indian Journal of Engineering \& Materials Science 2000; 7: 278-81.

[9] Kumar H, Kumar P, Chaudhary N, Bhardwaj R, Sharma GD, Venkatesu $\mathrm{P}$, et al. Temperature effect on the performance of phthalocyanine based photovoltaic devices. Indian Journal of Engineering \& Materials Science 2010; 17: 358-62.

[10] Nurfazliana MF, Kamaruddin SA, Alias MS, Nafarizal N, Saim $H$, Sahdan MZ. Zinc Oxide Nanostructures for Efficient Energy Conversion in Organic Solar Cell. Journal of Technology Innovations in Renewable Energy 2014; 3(1): 31-5.

http://dx.doi.org/10.6000/1929-6002.2014.03.01.5 
[11] Arranz-Andrés J, Blau WJ. Enhanced device performance using different carbon nanotube types in polymer photovoltaic devices. Carbon 2008; 46(15): 2067-75. http://dx.doi.org/10.1016/j.carbon.2008.08.027

[12] Bundgaard E, Krebs FC. Low band gap polymers for organic photovoltaics. Solar Energy Materials and Solar Cells 2007; 91(11): 954-85.

http://dx.doi.org/10.1016/j.solmat.2007.01.015

[13] Cai W, Gong X, Cao Y. Polymer solar cells: Recent development and possible routes for improvement in the performance. Solar Energy Materials and Solar Cells 2010; 94(2): 114-27.

http://dx.doi.org/10.1016/j.solmat.2009.10.005

[14] Mozer AJ, Sariciftci NS. Conjugated polymer photovoltaic devices and materials. Comptes Rendus Chimie 2006; 9(56): 568-77.

http://dx.doi.org/10.1016/j.crci.2005.03.033

[15] Reyes-Reyes M, López-Sandoval R, Liu J, Carroll DL. Bulk heterojunction organic photovoltaic based on polythiophenepolyelectrolyte carbon nanotube composites. Solar Energy Materials and Solar Cells 2007; 91(15-16): 1478-82.

http://dx.doi.org/10.1016/j.solmat.2007.04.023

[16] Wienk MM, Struijk MP, Janssen RAJ. Low band gap polymer bulk heterojunction solar cells. Chemical Physics Letters 2006; 422(4-6): 488-91.

http://dx.doi.org/10.1016/j.cplett.2006.03.027

[17] Zhao DW, Tan ST, Ke L, Liu P, Kyaw AKK, Sun XW, et al. Optimization of an inverted organic solar cell. Solar Energy Materials and Solar Cells 2010; 94(6): 985-91. http://dx.doi.org/10.1016/j.solmat.2010.02.010

[18] Green MA, Emery K, Hishikawa Y, Warta W. Solar cell efficiency tables (version 37). Progress in Photovoltaics: Research and Applications 2011; 19(1): 84-92.

http://dx.doi.org/10.1002/pip.1088

[19] Service RF. Outlook Brightens for Plastic Solar Cells. Science 2011 April 15, 2011; 332(6027): 293.

[20] Jørgensen M, Norrman K, Krebs FC. Stability/degradation of polymer solar cells. Solar Energy Materials and Solar Cells 2008; 92(7): 686-714.

http://dx.doi.org/10.1016/j.solmat.2008.01.005

[21] Heremans P, Cheyns D, Rand BP. Strategies for Increasing the Efficiency of Heterojunction Organic Solar Cells: Material Selection and Device Architecture. Accounts of Chemical Research 2009; 42(11): 1740-7. http://dx.doi.org/10.1021/ar9000923

[22] Minnaert B, Burgelman M. Efficiency Potential of Organic Bulk Heterojunction Solar Cells. Progress in Photovoltaics: Research and Applications 2007; 15: 741-8.

http://dx.doi.org/10.1002/pip.797

[23] Gupta D, Mukhopadhyay S, Narayan KS. Fill factor in organic solar cells. Solar Energy Materials and Solar Cells 2010; 94(8): 1309-13. http://dx.doi.org/10.1016/j.solmat.2008.06.001

[24] Muhammad FF, Sulaiman K. Photovoltaic performance of organic solar cells based on DH6T/PCBM thin film active layers. Thin Solid Films 2011; 519(15): 5230-3.

http://dx.doi.org/10.1016/j.tsf.2011.01.165

[25] Poortmans J, Arkhipov V. Thin Film Solar Cells Fabrication, Characterization and Applications. West Sussex PO19 8SQ, England: John Wiley \& Sons Ltd.; 2006. http://dx.doi.org/10.1002/0470091282

[26] Guo T-F, Wen T-C, L'Vovich Pakhomov G, Chin X-G, Liou S$\mathrm{H}$, Yeh $\mathrm{P}-\mathrm{H}$, et al. Effects of film treatment on the performance of poly(3-hexylthiophene)/soluble fullerenebased organic solar cells. Thin Solid Films 2008; 516(10): 3138-42.

http://dx.doi.org/10.1016/j.tsf.2007.08.066
[27] Spanggaard H, Krebs FC. A brief history of the development of organic and polymeric photovoltaics. Solar Energy Materials and Solar Cells 2004; 83(2-3): 125-46. http://dx.doi.org/10.1016/i.solmat.2004.02.021

[28] Chen L-M, Hong Z, Li G, Yang Y. Recent Progress in Polymer Solar Cells: Manipulation of Polymer: Fullerene Morphology and the Formation of Efficient Inverted Polymer Solar Cells. Advanced Materials 2009; 21(14-15): 1434-49. http://dx.doi.org/10.1002/adma.200802854

[29] Dennler G, Sariciftci NS. Flexible Conjugated Polymer-Based Plastic Solar Cells: From Basics to Applications. Proceedings of the IEEE 2005; 93(8): 1429-39. http://dx.doi.org/10.1109/JPROC.2005.851491

[30] Krebs FC. All solution roll-to-roll processed polymer solar cells free from indium-tin-oxide and vacuum coating steps. Organic Electronics 2009; 10(5): 761-8. http://dx.doi.org/10.1016/j.orgel.2009.03.009

[31] Liu F, Shao S, Guo X, Zhao Y, Xie Z. Efficient polymer photovoltaic cells using solution-processed $\mathrm{MoO} 3$ as anode buffer layer. Solar Energy Materials and Solar Cells 2010; 94(5): 842-5.

http://dx.doi.org/10.1016/j.solmat.2010.01.004

[32] Djara V, Bernède JC. Effect of the interface morphology on the fill factor of plastic solar cells. Thin Solid Films 2005; 493(1-2): 273-7. http://dx.doi.org/10.1016/j.tsf.2005.06.098

[33] Hayashi Y, Hamada K, Takagi K, Takasu A, Takagi S, Soga $\mathrm{T}$, editors. Investigation of PCBM Concentration on Photovoltaic Characteristics of Polymer Solar Cells with Blends of P3HT and PCBM. Conference Record of the 2006 IEEE $4^{\text {th }}$ World Conference on Photovoltaic Energy Conversion; 2006 May 2006.

[34] Maennig B, Drechsel J, Gebeyehu D, Simon P, Kozlowski F, Werner A, et al. Organic p-i-n solar cells. Applied Physics A: Materials Science and Processing 2004; 79(1): 1-14. http://dx.doi.org/10.1007/s00339-003-2494-9

[35] Cheyns D, Poortmans J, Gommans H, Genoe J, Heremans $P$. Stacked organic solar cells increase efficiency. SPIE Newsroom 2007: 1-3.

[36] Hadipour A, de Boer B, Blom PWM. Organic Tandem and Multi-Junction Solar Cells. Advanced Functional Materials 2008; 18(2): 169-81. http://dx.doi.org/10.1002/adfm.200700517

[37] Kim JY, Lee K, Coates NE, Moses D, Nguyen T-Q, Dante M, et al. Efficient Tandem Polymer Solar Cells Fabricated by AllSolution Processing. Science 2007 July 13, 2007; 317(5835): 222-5.

[38] Yoo S, Potscavage Jr WJ, Domercq B, Han S-H, Li T-D, Jones SC, et al. Analysis of improved photovoltaic properties of pentacene/ $\mathrm{C}_{60}$ organic solar cells: Effects of exciton blocking layer thickness and thermal annealing. Solid-State Electronics 2007; 51(10): 1367-75.

http://dx.doi.org/10.1016/..sse.2007.07.038

[39] Vivo P, Jukola J, Ojala $M$, Chukharev V, Lemmetyinen $H$. Influence of Alq3/Au cathode on stability and efficiency of a layered organic solar cell in air. Solar Energy Materials and Solar Cells 2008; 92(11): 1416-20.

http://dx.doi.org/10.1016/j.solmat.2008.06.002

[40] Kao P-C, Chu S-Y, Huang H-H, Tseng Z-L, Chen Y-C. Improved efficiency of organic photovoltaic cells using tris (8hydroxy-quinoline) aluminum as a doping material. Thin Solid Films 2009; 517(17): 5301-4. http://dx.doi.org/10.1016/j.tsf.2009.03.147

[41] Cravino A, Sariciftci NS. Double-cable polymers for fullerene based organic optoelectronic applications. Journal of Materials Chemistry 2002; 12(7): 1931-43. http://dx.doi.org/10.1039/b201558g 
[42] Cravino A, Zerza G, Maggini M, Bucella S, Svensson M, Andersson MR, et al. A Soluble Donor-Acceptor DoubleCable Polymer: Polythiophene with Pendant Fullerenes. Monatshefte für Chemie / Chemical Monthly 2003; 134(4): 519-27. http://dx.doi.org/10.1007/s00706-002-0555-y

[43] Zerza G, Cravino A, Neugebauer H, Sariciftci NS, Gómez R, Segura JL, et al. Photoinduced Electron Transfer in Donor-Acceptor Double-Cable Polymers: Polythiophene Bearing Tetracyanoanthraquinodimethane Moieties. The Journal of Physical Chemistry A 2001; 105(17): 4172-6. http://dx.doi.org/10.1021/jp0037448

[44] Cureton LT, Beyer FL, Turner SR. Synthesis and characterization of hexafluoroisopropylidene bisphenol poly(arylene ether sulfone) and polydimethylsiloxane segmented block copolymers. Polymer 2010; 51(8): 1679-86. http://dx.doi.org/10.1016/j.polymer.2010.02.010

[45] Surapati M, Seino M, Hayakawa T, Kakimoto M-a. Synthesis of hyperbranched-linear star block copolymers by atom transfer radical polymerization of styrene using hyperbranched poly(siloxysilane) (HBPS) macroinitiator. European Polymer Journal 2010; 46(2): 217-25. http://dx.doi.org/10.1016/j.eurpolymj.2009.10.028

[46] Stalmach U, de Boer B, Videlot C, van Hutten PF, Hadziioannou G. Semiconducting Diblock Copolymers Synthesized by Means of Controlled Radical Polymerization Techniques. Journal of the American Chemical Society 2000; 122(23): 5464-72.

http://dx.doi.org/10.1021/ja000160a

[47] Masi JV, editor. Polymers: conductors, insulators, and active devices. Electrical Insulation Conference and Electrical Manufacturing \& Coil Winding Technology Conference, 2003 Proceedings; 2003 23-25 Sept 2003.

[48] Shirota Y. Organic materials for electronic and optoelectronic devices. Journal of Materials Chemistry 2000; 10(1): 1-25. http://dx.doi.org/10.1039/a908130e

[49] Koeppe R, Sariciftci NS. Photoinduced charge and energy transfer involving fullerene derivatives. Photochemical \& Photobiological Sciences 2006; 5(12): 1122-31. http://dx.doi.org/10.1039/b612933c

[50] Muhammad FF, Abdul Hapip Al, Sulaiman K. Study of optoelectronic energy bands and molecular energy levels of tris (8-hydroxyquinolinate) gallium and aluminum organometallic materials from their spectroscopic and electrochemical analysis. Journal of Organometallic Chemistry 2010; 695(23): 2526-31.

http://dx.doi.org/10.1016/j.jorganchem.2010.07.026

[51] Ye R, Baba M, Suzuki K, Mori K. Fabrication of highly airstable ambipolar thin-film transistors with organic heterostructure of $\mathrm{F}_{16} \mathrm{CuPc}$ and $\mathrm{DH}-\alpha 6 \mathrm{~T}$. Solid-State Electronics 2008; 52(1): 60-2.

http://dx.doi.org/10.1016/j.sse.2007.07.010

[52] Chen Z, Ikeda S, Saiki K. Sexithiophene films on cleaved $\mathrm{KBr}\left(\begin{array}{lll}1 & 0 & 0\end{array}\right)$ towards well-ordered semiconducting films. Materials Science and Engineering: B 2006; 133(1-3): 1959.

http://dx.doi.org/10.1016/j.mseb.2006.06.039

[53] Mu JY, Chen ZX, Luong TTT. X-ray diffraction investigations of well-ordered sexithiophene films deposited on flexible substrates. Journal of Materials Processing Technology 2009; 209(3): 1491-4. http://dx.doi.org/10.1016/j.jmatprotec.2008.03.055

[54] Sato T, Fujitsuka M, Shiro M, Tanaka K. Photoluminescence quenching in oligothiophene single crystal. Synthetic Metals 1998; 95(2): 143-8. http://dx.doi.org/10.1016/S0379-6779(98)00048-4

[55] Iosip MD, Destri S, Pasini M, Porzio W, Pernstich KP, Batlogg B. New dithieno[3,2-b: 2',3'-d]thiophene oligomers as promising materials for organic field-effect transistor applications. Synthetic Metals 2004; 146(3): 251-7. http://dx.doi.org/10.1016/j.synthmet.2004.08.004

[56] Murphy AR, Fréchet JMJ, Chang P, Lee J, Subramanian V. Organic Thin Film Transistors from a Soluble Oligothiophene Derivative Containing Thermally Removable Solubilizing Groups. Journal of the American Chemical Society 2004; 126(6): 1596-7. http://dx.doi.org/10.1021/ja039529x

[57] Yamanari T, Taima T, Sakai J, Saito K. Origin of the opencircuit voltage of organic thin-film solar cells based on conjugated polymers. Solar Energy Materials and Solar Cells 2009; 93(6-7): 759-61. http://dx.doi.org/10.1016/j.solmat.2008.09.022 